Revista Docência do Ensino

Superior

v. 1,2011

Thaïs Cristófaro Silva

UFMG

Hani Camille Yehia

UFMG

\section{SONORIDADE EM ARTES, SAÚDE E TECNOLOGIA}

\author{
SPEECH SOUNDS IN ARTS, HEALTH AND \\ TECHNOLOGICAL STUDIES
}

\section{RESUMO}

Este artigo apresenta o projeto intitulado "Sonoridade em Artes, Saúde e Tecnologia", cujos resultados se encontram disponibilizados em www.fonologia.org. Através da divulgação gratuita de material de ensino e de aprendizagem das áreas de Fonética e Fonologia de forma interativa, o projeto contribui com a formação de profissionais de várias áreas do conhecimento, entre elas: Letras, Artes Cênicas, Música, Fonoaudiologia, Psicologia e Tecnologia da Fala. O site é apresentado de maneira que o usuário possa praticar um determinado conteúdo quantas vezes sejam necessárias, o que permite maior sucesso, uma vez que pessoas diferentes têm tempos diferentes para sedimentar conteúdos específicos. O sucesso do projeto pode ser comprovado pelo crescente número de acessos ao site, tanto de usuários do Brasil quanto do exterior. O projeto contribui com o desenvolvimento de novas metodologias de ensino e socializa o conhecimento específico de maneira abrangente para a comunidade em geral.

Palavras-Chave: Fonética. Fonologia. Fala. Som. Linguística.

\section{ABSTRACT}

This paper presents the project entitled "Speech Sounds in Arts, Health and Technological Studies", whose results are available at www.fonologia.org. The project offers free dissemination of interactive learning materials in the areas of Phonetics and Phonology contributing to the training of professionals from different fields of knowledge, including: Languages, Drama, Music, Speech Therapy, Psychology and Speech Technology. The site mentioned above is presented in a way that users can practice a given subject as often and as many times as they want, allowing successful learning since different people have different learning rates for specific technical subjects. The success of the project can be demonstrated by the growing number of hits the site receives from Brazilian users as well as foreign visitors. The project contributes to the development of new teaching methodologies and socializes technical knowledge in a comprehensive manner for the community in general.

Keywords: Phonetics. Phonology. Speech. Sound, Linguistics.
Universidade Federal de Minas Gerais

Correspondência/Contato

Av. Antônio Carlos, 6627

Pampulha: 31270-901

BELO HORIZONTE - MG

revistadocenciadoensinosuperior@ufmg.br
Keywords: Phonetics. Phonology. Speech. Sound, Linguistics. 


\section{INTRODUÇÃO}

Ao apresentarmos o título de nosso trabalho para a língua inglesa nos deparamos com a dificuldade para traduzirmos o termo "sonoridade". O termo tem origem no latim sonoritate e tem a seguinte definição no Dicionário Michaelis Online: "Propriedade de produzir ou de formar sons". Ao solicitarmos a tradução deste termo no Dicionário Michaelis Online obtivemos "sonority". Contudo, "sonority" não é um termo que conste nos dicionários de língua inglesa da Cambridge University Press. Com esta breve apreciação da dificuldade de tradução do termo "sonoridade", justificamos a tradução do nosso título e apresentamos a pergunta de pesquisa que motivou a criação do nosso site www.fonologia.org: Como podemos ensinar aos alunos sobre a dinamicidade envolvida na produção dos sons da fala, tendo especificidade no português brasileiro?

Tradicionalmente, o ensino de produção da fala é compreendido como sendo do domínio da Fonética. A Fonética pode ser definida como "a ciência que apresenta os métodos para a descrição, classificação e transcrição dos sons da fala" (CRISTÓFARO SILVA, 2010, p. 23). A Fonética pode ser dividida em: articulatória, auditiva, acústica e instrumental. A Fonética Articulatória compreende o estudo da produção da fala do ponto de vista fisiológico e articulatório. A Fonética Auditiva compreende o estudo da percepção da fala. A Fonética Acústica compreende o estudo das propriedades físicas dos sons da fala. A Fonética Instrumental compreende o estudo das propriedades dos sons da fala com o apoio de instrumentos laboratoriais. A Fonética é, portanto, a ciência que estuda os sons da fala como são pronunciados pelos falantes ao fazerem uso efetivo de sua língua, sobretudo para propósitos de comunicação.

Outra ciência relacionada com os sons da fala é denominada Fonologia. A Fonologia é a ciência que estuda os princípios que regem a organização dos sons nas línguas. Pode-se dizer que a Fonologia estuda a organização gramatical do componente sonoro das línguas. A relação entre a Fonética e Fonologia é complementar e a relação entre estas disciplinas tem ocupado espaço importante no debate atual (CRISTÓFARO SILVA, 2006; DEMOLIN, 2005; PIERREHUMBERT; BECKMAN; LADD, 2000). Pode-se dizer, por exemplo que a Fonologia busca explicar de que modo pronúncias como ['plastiku], ['plast $\left.\int i k v\right]$ ou ['prast $\left.\int i k u\right]$ se relacionam com a palavra que tem o significado de "plástico". A Fonologia busca explicar também por que uma palavra como "sgrof" 
não é possível em português, enquanto a palavra "esgrofe" não ocorre em português, mas, potencialmente, poderia existir.

Tradicionalmente, assume-se que os sons estudados pela Fonética têm realização efetiva e são transcritos entre colchetes: ['bala]. Já a Fonologia apresenta a representação abstrata dos sons da fala - portanto não pronunciáveis - que são transcritos entre barras transversais: /'bala/. As transcrições fonéticas e fonológicas podem ser equivalentes, como ilustrado acima para o exemplo "bala". Mas as transcrições fonéticas e fonológicas podem ser consideravelmente diferentes, por exemplo, na palavra "opção": [opi'sãu] e /op'sano/. A relação entre a forma fonética e fonológica depende dos diversos modelos teóricos que tentam explicar como se produz e se organiza a sonoridade nas línguas naturais.

Considerando-se as observações feitas nesta seção, tornam-se claros os desafios a serem enfrentados para o ensino e aprendizagem das disciplinas de Fonética e Fonologia. Tradicionalmente, os estudos nesta área são feitos em livros impressos (BISOL, 1999; CALLOU; LEITE, 2000; CAGLIARI, 2002; CAVALIERE, 2005; CRISTÓFARO SILVA, 2010). Em livros, dada a natureza da mídia impressa, a fala é visualizada como estática. Contudo, a fala é um evento dinâmico em que órgãos do corpo humano se movimentam e se organizam com o objetivo de produzir sinais acústicos que expressem a sonoridade das línguas. Portanto, seria adequado construir material didático de ensino e aprendizagem da sonoridade que apresentasse os eventos da fala como dinâmicos. Foi neste contexto que tivemos a motivação para descrever o site de ensino on-line que é apresentado neste artigo.

\section{CONTEÚDO DO SITE}

A Figura 1 ilustra a página inicial do site que nós, autores deste artigo, construímos com o apoio técnico dos alunos Fernando Oliveira, da Escola de Engenharia, e Diana Souza, da Faculdade de Letras. O projeto intitulado "Sonoridade em Artes Saúde e Tecnologia" contou com o apoio da Pró-Reitoria de Graduação da Universidade Federal de Minas Gerais nos anos de 2008 e 2009.1 O projeto teve ainda duas premiações, como Menção Honrosa, nas duas Semanas do Conhecimento de que participou na Universidade Federal de Minas Gerais.

1 Editais PEG (Programa de Ensino de Graduação) Processos PEG-049 (março-dezembro de 2008) e PEG052 (março-dezembro 2009). Os autores e coordenadores do projeto destacam o caráter de dedicação e participação exemplar dos bolsistas envolvidos na construção do site descrito neste artigo. 


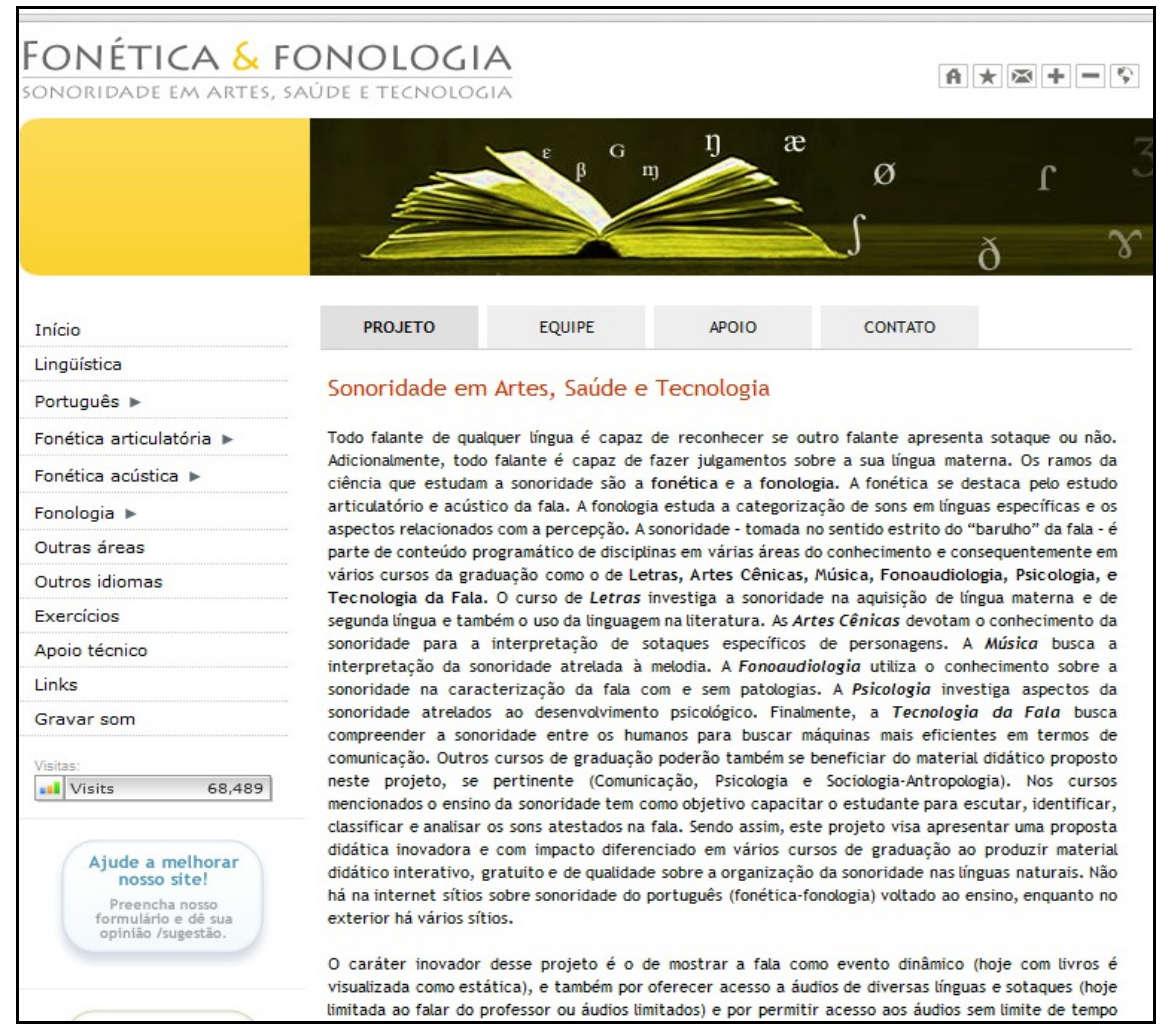

Figura 1: Página inicial do site www.fonologia.org

O menu do lado esquerdo da Figura 1 indica o conteúdo da página neste momento. No restante desta seção descreveremos, brevemente, o conteúdo indicando, sobretudo, inovações decorrentes do formato virtual de apresentação do conteúdo. A página inicial está relacionada ao item "Início" no menu e apresenta quatro abas na parte superior:

1) Projeto: ilustra informações gerais sobre o site;

2) Equipe: lista os coordenadores e os alunos bolsistas;

3) Apoio: lista os laboratórios e as instituições de apoio ao projeto;

4) Contato: indica o e-mail de contato com o projeto:

foneticaefonologia@gmail.com.

O segundo item do menu é "Linguística" e tem por objetivo contextualizar a Fonética e a Fonologia como domínios do conhecimento vinculados à Linguística. O terceiro item do menu é "Português" . O quarto item do menu é "Fonética Articulatória" e é dividida em:

a) Introdução;

b) Aparelho Fonador; 
c) Sons do português: consoantes e vogais;

d) Quadro fonético;

e) Desvios da fala;

f) Sons não utilizados na fala.

As seções (b) e (c) têm conteúdo dinâmico onde se indicam os órgãos envolvidos na produção da fala e podem-se observar em diagrama os movimentos articulatórios envolvidos na produção de cada som individual, bem como escutar cada som e assistir em vídeo à produção de algumas palavras ilustrativas. A seção (d) ilustra o quadro fonético da Associação Internacional de Fonética e indica os sons que ocorrem em português. A seção (e) ainda necessita ser construída e a seção (f) ilustra a produção de sons não utilizados na fala, por exemplo, arroto, engasgo, espirro, pigarro, ronco, soluço e tosse. O quinto item do menu é "Fonética Acústica" e é dividido em:

a) Introdução;

b) O som;

c) Acústica e fonação;

d) Sons do português: consoantes e vogais;

e) Softwares.

As seções (b) e (c) oferecem o aporte teórico para os estudos em acústica da fala. A seção (d) ilustra o correlato acústico, em figuras de forma de onda e espectrograma, de cada um dos sons apresentados na seção de "Fonética Articulatória" e apresenta os áudios correspondentes. O sexto item do menu é "Fonologia" e é dividido em:

a) Introdução;

b) Modelos fonológicos: Estruturalismo, Modelos Lineares e Modelos Não Lineares;

c) Quadro Fonêmico.

A seção (b) apresenta os principais aspectos de vários modelos fonológicos e ainda deve ser expandida. O sétimo item no menu é "Outras áreas" e tem por objetivo indicar a contribuição da Fonética e da Fonologia aos estudos de outras áreas do conhecimento além da Linguística. Tais áreas são: a) Artes Cênicas, b) Fonoaudiologia, c) Música, d) Psicologia e e) Tecnologia de Fala. Ainda há necessidade de ampliarmos es- 
ta seção. O oitavo item do menu é "Outros idiomas" e também deverá ser ampliado em etapas futuras. O nono item do menu é "Exercícios" e é dividido em:

a) Fonética Articulatória;

b) Fonologia;

c) Transcrições;

d) Ortografia, fonética e gramática tradicional.

Este nono item permite que os usuários do site pratiquem o conteúdo em exercícios e façam aferição do conhecimento adquirido ao conferirem as respostas. $\mathrm{O}$ décimo item do menu é "Apoio Técnico" e oferece referências de fontes fonéticas específicas e de acesso a programas relevantes para o estudo da sonoridade. O décimo primeiro item do menu é "Links" e oferece direcionamento para sites diversos de interesses na área de sonoridade da fala. O décimo segundo e último item do menu é: "Gravar som". Esta seção apresenta um mapa do Brasil e oferece a opção de o usuário contribuir com uma amostra de sua fala ao ler um texto disponibilizado por nós. A ideia é criarmos um acervo com o mesmo conteúdo, ou seja, a leitura de um texto, oferecendo amostras de fala do Brasil de norte a sul e leste a oeste. Esta etapa está em fase de implementação. As seções são independentes e podem ser estudadas cada uma separadamente, ou podem ser estudadas em sequência descendente do menu que corresponde à evolução do conteúdo teórico.

Abaixo do menu indica-se o número de visitantes desde fevereiro de 2009, quando o site foi disponibilizado na Internet para o público em geral. A Figura 2 indica que, além de usuários do português brasileiro (em torno de $74 \%$ dos acessos), o site teve visitantes de 45 países, incluindo o Brasil, de fevereiro de 2009 a setembro de 2011: Argentina, Portugal, Estados Unidos, Angola, Moçambique, Paraguai, Macau, Colômbia, França, Uruguai, Peru, Rússia, México, Espanha, Vietnã, Malawi, Japão, Polônia, Itália, Dinamarca, Noruega, Coreia do Sul, Alemanha, Austrália, Canadá, Bolívia, Guatemala, Reino Unido, República Tcheca, Chile, Indonésia, Irlanda, Costa Rica, Equador, Lituânia, Suíça, Finlândia, Suécia, Turquia, Cabo Verde, Filipinas, România, Nicarágua e outros países não identificados pelo contador de visitas. 


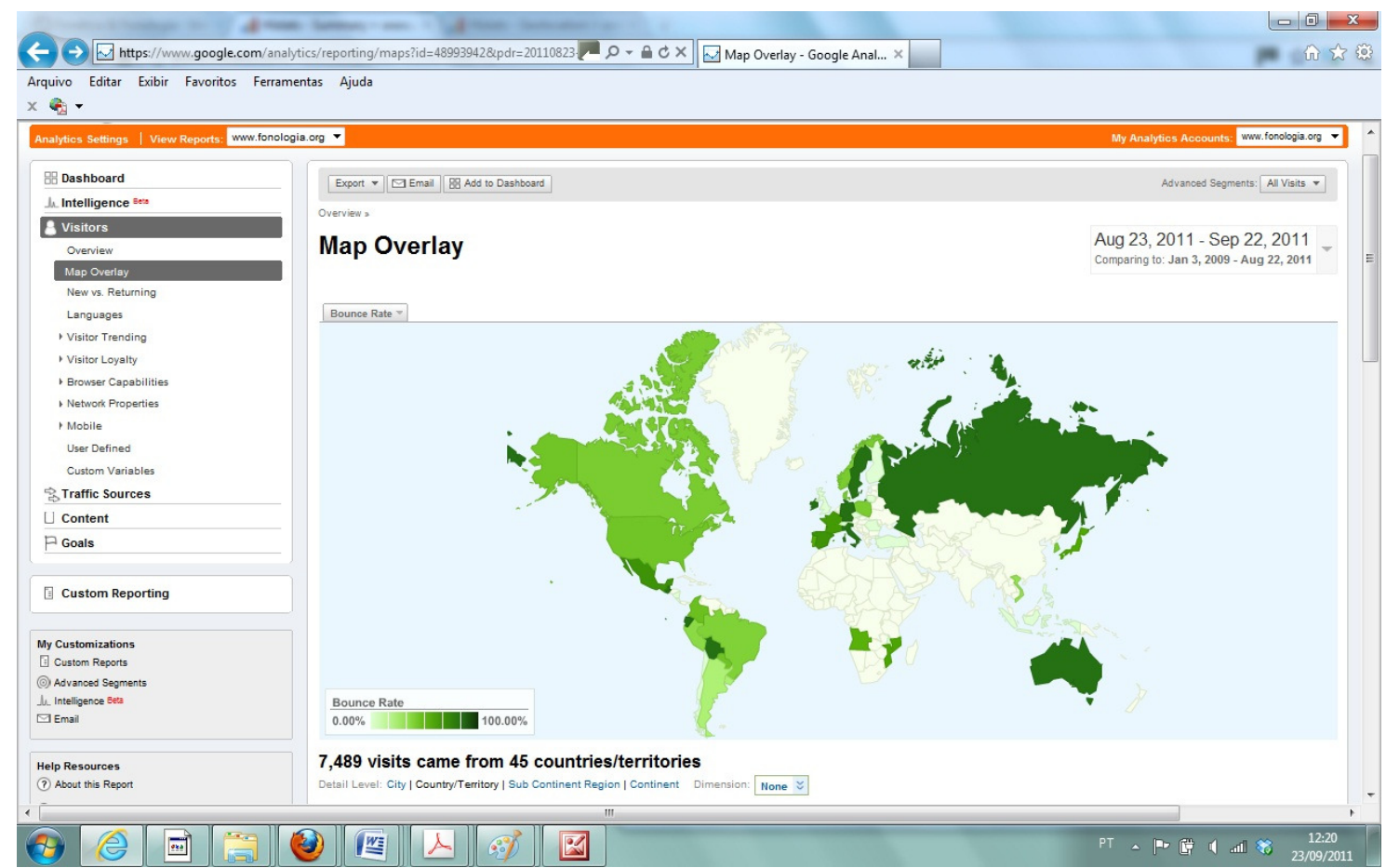

Figura 2: Tráfego de visitantes de www.fonologia.org

Assim, além de ser um veículo de apoio ao ensino de Fonética e Fonologia do português o projeto "Sonoridade em Artes, Saúde e Tecnologia" permite o acesso de estudantes de português como língua estrangeira que são residentes em outros países, bem como de todas as pessoas interessadas no português em geral. ${ }^{2}$

\section{INEDITISMO PARA O PORTUGUÊS}

O ineditismo do projeto "Sonoridade em Artes, Saúde e Tecnologia" pode ser inferido pelo grande número de visitantes que o site tem recebido. Seu sucesso decorre da divulgação de material de ensino e aprendizagem disponibilizado gratuitamente para a comunidade em geral, com conteúdo original e inovador. O caráter original advém da disponibilização de material de caráter dinâmico de rotinas articulatórias envolvidas na produção dos sons da fala. Os usuários visualizam passo a passo, em movimento, como se dá a articulação dos sons do português brasileiro. Adicionalmente, cada som é ilustrado em contexto de palavras específicas com acesso a áudio e vídeo. $\mathrm{O}$ site é apresentado de maneira que o aluno possa praticar um determinado conteúdo

2 Recentemente, a Profa. Thaïs Cristófaro Silva esteve na Universidade de Córdoba, na Argentina para ministrar curso na área de Fonética e Fonologia, tendo sido convidada pelos professores que utilizam o site www.fonologia.org. Professores da Universidade do Texas, nos Estados Unidos da América, também fazem uso do site para o ensino de PLE (Português como Língua Estrangeira). 
quantas vezes sejam necessárias, o que permite maior sucesso, uma vez que pessoas diferentes têm tempos diferentes para sedimentar conteúdos específicos.

O material do site, além de ser importante aos estudos da Fonética e Fonologia, tem sido utilizado em consultórios de fonoaudiologia para indicar aos pacientes e seus cuidadores como procede a produção da fala. O material em áudio e vídeo tem sido também utilizado por usuários surdos que tenham interesse em vocalizar os sons da fala. Mostra-se, portanto, o caráter inovador não apenas científico e de divulgação, mas de extensão, ao ter utilidade para a comunidade em geral.

A seção de "Fonética Acústica" oferece conteúdo inovador e permite aos usuários o acesso a informações antes restritas. Isto porque nos cursos de Letras as disciplinas de Fonética e Fonologia restringem-se, de maneira geral, ao conteúdo de "Fonética Articulatória". Esperamos que com o acesso livre e gratuito ao conteúdo de "Fonética Acústica" haja expansão deste tema em cursos de Letras e afins.

A seção de "Exercícios" tem caráter inovador, ao permitir que o aluno pratique determinado conteúdo quantas vezes sejam necessárias. A aferição do conteúdo permite a autoavaliação e o usuário pode verificar como desenvolve a apropriação do conteúdo estudado.

A seção de "Gravar som", ainda em implementação, tem caráter inovador por apresentar amostras de diversas variedades do português do Brasil. Ou seja, poderemos ter acesso ao áudio de um falante do interior do Acre ou do oeste do Paraná. O acesso aos áudios se dará por filtros de: estados/cidades, sexo, idade e grau de instrução do participante.

Em resumo, o projeto "Sonoridade em Artes, Saúde e Tecnologia” oferece livre e gratuitamente o acesso ao conhecimento nas áreas de Fonética e Fonologia, permite a aferição de conteúdo pelos usuários, apresenta instrumental relevante para a sociedade quando em busca de esclarecimentos sobre a fala e permite o conhecimento dos vários falares do português.

\section{TRANSDICIPLINARIDADE}

Mencionamos ao longo das seções anteriores a relação da Fonética e da Fonologia com várias áreas do conhecimento. Nesta seção pretendemos indicar a transdiciplinaridade do conteúdo disponibilizado pelo projeto "Sonoridade em Artes, Saúde e Tecnologia". A sonoridade - tomada no sentido estrito dos sinais acústicos da fala - é 
parte de conteúdo programático de disciplinas em várias áreas do conhecimento e consequentemente é ministrada em vários cursos de graduação, como os de Letras, Artes Cênicas, Música, Fonoaudiologia, Psicologia e Tecnologia da Fala. O curso de Letras investiga a sonoridade na aquisição/uso de língua materna e de segunda língua e também o uso da linguagem na literatura. Adicionalmente, as disciplinas de Linguística nos cursos de Letras buscam formular teorias que visam a explicar como se organiza o conhecimento gramatical das línguas naturais. As Artes Cênicas devotam o conhecimento da sonoridade, sobretudo, para a interpretação de sotaques específicos de personagens. A Música busca a interpretação da sonoridade atrelada à melodia. $\mathrm{O}$ canto lírico pode ser reproduzido por cantores de várias nacionalidades e o conhecimento da sonoridade contribui para que a performance seja mais bem-sucedida. A Fonoaudiologia utiliza o conhecimento sobre a sonoridade na caracterização da fala com e sem patologias, sobretudo na fala infantil. Contudo, o conhecimento da sonoridade permite apoio a disfuncionalidades da fala relacionadas com a fala adulta (como pessoas que sofreram sequelas de fala em traumatismo craniano, afasias, AVCs, entre outras). Ainda na Fonoaudiologia, e com estreita relação com a Pedagogia, há os estudos sobre o desenvolvimento da leitura e escrita. O impacto da sonoridade na alfabetização é altamente relevante e o apoio do conhecimento das áreas de Fonética e Fonologia é crucial para o sucesso da alfabetização e apropriação da linguagem escrita, bem como da leitura. A Psicologia investiga aspectos da sonoridade atrelados ao desenvolvimento psicológico, sobretudo em relação ao desenvolvimento psicológico e da fala. Disfuncionalidades psicológicas podem também ter contribuições da sonoridade. Finalmente, a Tecnologia da Fala busca métodos mais eficientes de codificação, síntese e reconhecimento da fala em sistemas de comunicação. Além disso, a interação homem-máquina tem se mostrado muito importante e, para seu amplo sucesso, temos de conhecer sobre a sonoridade das línguas em geral. Outros cursos de graduação também têm interesse no material didático disponibilizado pelo projeto, como a Comunicação, a Física Teórica, a Sociologia e a Antropologia. O projeto foi intitulado "Sonoridade em Artes, Saúde e Tecnologia" com o objetivo de indicar a transdisciplinaridade dos temas abordados. Artes (pelas Letras, Artes Cênicas e Música), Saúde (pela Fonoaudiologia e Psicologia) e Tecnologia (pela Computação e Engenharia Elétrica). Ou seja, o projeto apresenta uma proposta didática de caráter transdisciplinar, inovadora e com impacto diferenciado em vários cursos de graduação, ao produzir material didático interativo, gratuito e de qualidade sobre a organização da sonoridade nas línguas naturais. 


\section{VANTAGENS DO ENSINO VIRTUAL SOBRE A MÍDIA IMPRESSA}

A mídia impressa representa uma revolução no processo de disseminação do conhecimento humano, predominando desde os tempos de Gutemberg até os dias de hoje. No entanto, com o advento da mídia eletrônica, uma nova revolução vem ocorrendo desde a década de 1990. Inicialmente com o surgimento do hipertexto (Wikipedia) e, posteriormente, com a penetração capilar da Internet, a informação passou a ser acessível de forma muito mais abrangente do que na mídia impressa.

No caso específico do estudo das línguas, é simplesmente impossível expressar, por meio da mídia impressa, as informações necessárias para que seja possível reproduzir os sons da fala de forma precisa. Neste contexto, a mídia eletrônica permite que sons e vídeos sejam adicionados ao texto e a imagens, transformando o leitor em espectador e ouvinte. A Figura 3 ilustra este ponto ao mostrar que, por meio de uma simples imagem, não é possível descrever os movimentos associados à produção dos sons do Português. Ao ser acessado pelo site www.fonologia.org, pode-se observar o movimento dos articuladores (língua, lábios, mandíbula, etc.) por meio da animação de um corte sagital do trato vocal e também o movimento facial, por meio do vídeo real de um locutor. Além disso, podem-se ouvir, simultaneamente, os sons produzidos.

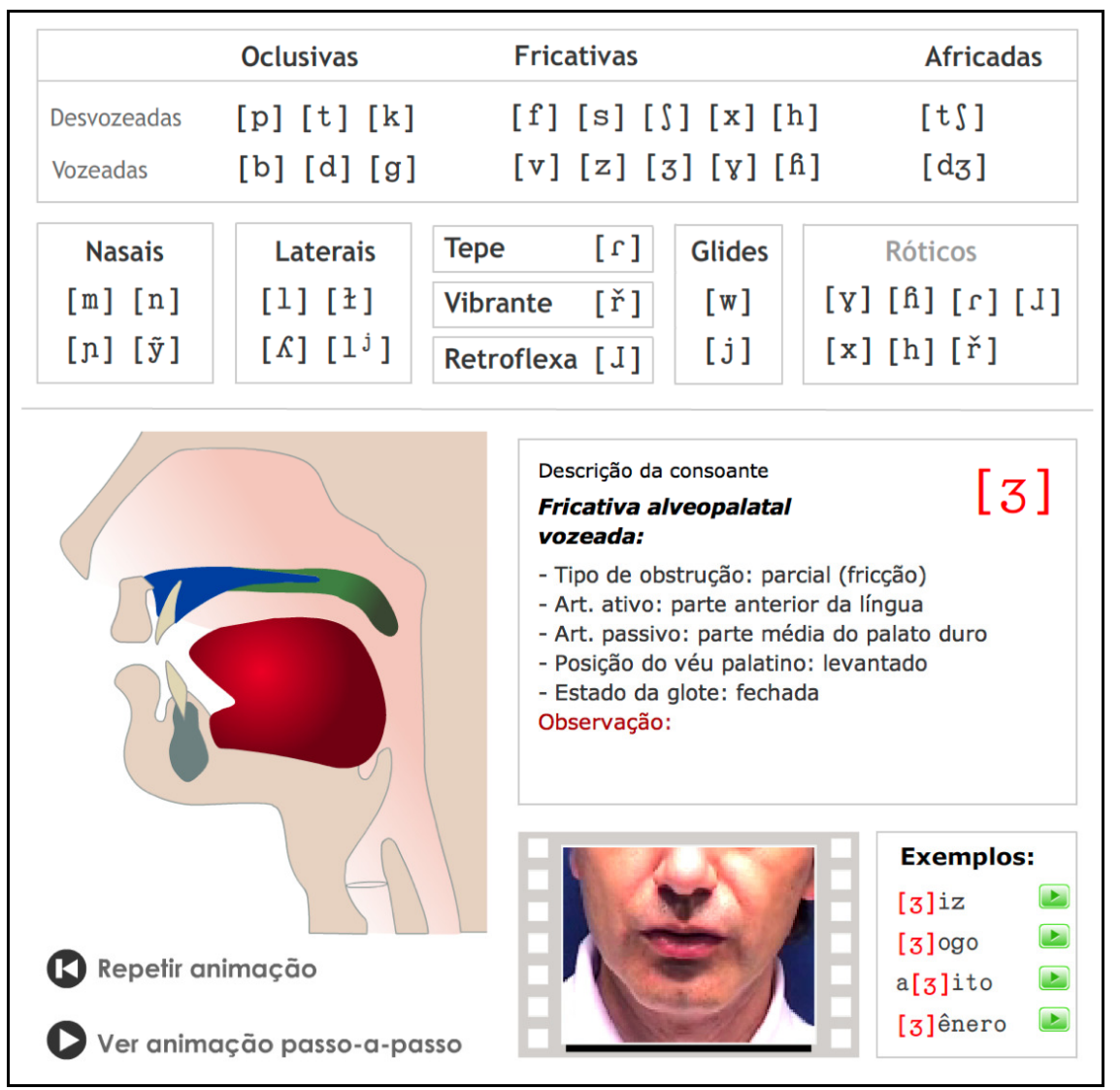

Figura 3: Corte sagital e quadro de um vídeo durante a produção da fala 


\section{INTERATIVIDADE}

A mídia eletrônica, além de fornecer ao leitor-espectador-ouvinte um conjunto muito mais completo de informações do que a mídia impressa, permite que o aprendizado seja realizado de maneira interativa. Desta forma, ao se observar movimentos faciais e do trato vocal, é possível reproduzir e, por meio de uma câmera e de um microfone (disponíveis em qualquer computador atual do tipo notebook), registrar os próprios sons e vídeos para comparação com os padrões disponíveis no site www.fonologia.org. Com um pouco mais esforço, pode-se também utilizar um software de análise acústica como o Praat (BOERSMA; WEENICK, 2011) para comparar o espectrograma dos próprios sons com aqueles disponibilizados na forma ilustrada na Figura 4.

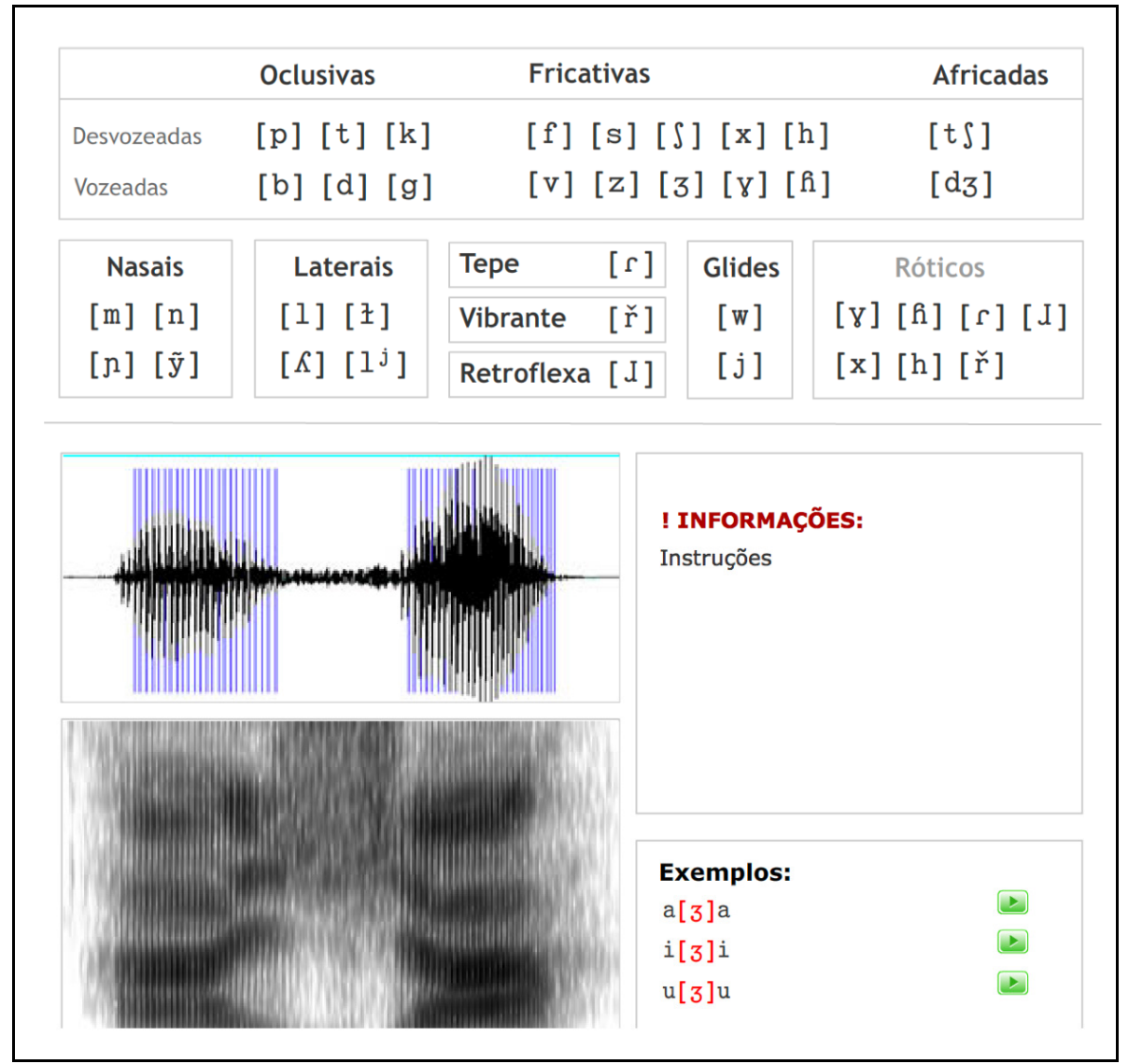

Figura 4: Forma de onda e espectrograma da elocução [aza]

Desta forma, se bem explorado, o site do projeto "Sonoridade em Artes, Saúde e Tecnologia" permite uma aceleração significativa do ritmo de aprendizagem do conteúdo de Fonética e de Fonologia, com ênfase no português brasileiro. Cabe aqui observar que o aprendizado por meio da reprodução de movimentos e sons elimina o processo de decodificação e recodificação de símbolos fonéticos, necessário na apren- 
dizagem por meio de mídia impressa. Este processo restringe informações e, potencialmente, insere distorções de pronúncia que têm menos chance de ocorrer quando se aprende diretamente a partir da observação de sons e movimentos. $\mathrm{O}$ uso de recursos multimídia (isto é, texto, imagem, áudio e vídeo) facilita também a, assim chamada, aprendizagem ativa, uma vez que estimula a reprodução dos estímulos recebidos de forma muito mais ativa do que a mídia impressa.

\section{CONSTRUÇÃO CONSTANTE}

O site www.fonologia.org do projeto "Sonoridade em Artes, Saúde e Tecnologia" está em contínuo processo de construção, buscando explorar da maneira mais eficiente possível os recursos disponíveis na Internet. Neste sentido, por exemplo, como explicado na Seção 2, estamos realizando a coleta de amostras do português falado nas mais diversas localidades do país, para a construção de uma base de dados que, ao longo dos anos, permitirá o estudo das diversas variedades geográficas da língua. Além disso, o site ainda contém seções sem conteúdo, as quais estão sendo gradual e progressivamente elaboradas.

\section{CONCLUSÃO}

O projeto "Sonoridade em Artes, Saúde e Tecnologia" aqui apresentado surgiu da necessidade de fornecer, para o português brasileiro, informações multimodais e interativas sobre o conteúdo de Fonética e Fonologia que já existiam para diversas línguas estrangeiras. Durante o processo de preenchimento desta lacuna, o site www.fonologia.org mostrou-se, além de importante para que nossa língua possa ser registrada e assimilada de forma completa, fundamental para que possamos compreender o próprio processo de evolução do português. Esperamos, assim, estar desenvolvendo uma ferramenta por meio da qual possamos explorar a produção sonora da língua portuguesa como um todo.

\section{REFERÊNCIAS BIBLIOGRÁFICAS}

BISOL, Leda (Org.). Introdução aos estudos de fonologia do português brasileiro. 2. ed. Porto Alegre: EDPUCRS, 1999. 
BOERSMA, P.; WEENINK, D. Praat: doing phonetics by computer [Computer program]. Version 5.2.44, Consultado em 23 September 2011 em http://www.praat.org/. 2011.

CAGLIARI, L. C. Análise fonológica: introdução à teoria e à prática com especial destaque para o modelo fonêmico. Campinas: Mercado de Letras, 2002.

CALLOU, D. I.; LEITE, Y. Iniciação à fonética e à fonologia. 7. ed. Rio de Janeiro: Jorge Zahar, 2000.

CAVALIERE, R. Pontos essenciais em fonética e fonologia. Rio de Janeiro: Lucerna, 2005. (Coleção Pontos Essenciais.)

CRISTÓFARO SILVA, T. Fonética e Fonologia do Português: roteiro de estudos e guia de exercícios. 10. ed. São Paulo: Contexto, 2010.

CRISTÓFARO SILVA, T. Fonética e Fonologia: Perspectivas Complementares. Revista de Estudos da Linguagem, Vitória da Conquista, v. 3, p. 25-40, 2006.

CAMBRIDGE UNIVERSITY PRESS DICTIONARIES.

http:/ / dictionary.cambridge.org/. Acesso em: setembro 2011.

DEMOLIN, D. The integration of phonetics and phonology. Estudos Linguísticos, Campinas, v. 34, 2005.

DICIONÁRIO MICHAELIS ONLINE. http://michaelis.uol.com.br /. Acesso em: setembro 2011.

PIERREHUMBERT, J.; BECKMAN, M.; LADD, R. Conceptual Foundations of Phonology as a Laboratory Science. In: N. BURTON-ROBERTS, CARR P.; DOCHERTY, G. (Ed.). Phonological Knowledge. Oxford: Oxford University Press, 2000. (Oxford Linguistics Series.) 